\title{
TWO CASES OF CHYLOUS EFFUSION
}

\author{
By
}

M. H. Pappworth, M.D. (LiverP.), M.R.C.P. (Lond.)

Turbid effusions are divided into three types: (I) Chylous ; (2) Chyliform; (3) Pseudo-chylous. ('Oxford Medicine,' 1927; 'Osler's 'Medicine;' I935; 'Price's Text Book of Medicine,' 1936.)

Type (I) is pure chyle; type (2) is fat in emulsion due to fat liberated by the breaking down of leucoytes and endothelial cells which have undergone fatty degeneration; type (3) is where the opalescence is not due to fat but calcium phosphate or a lecithin-globulin complex.

This classification is artificial, unsatisfactory and based on unsound biochemical investigation. Gandin (1913) was the first person to question the possibility of such differentiation. Collecting all recorded cases in the literature, he found wide discrepancies and stated that but 0.1 per cent. of finely emulsified fat is necessary to produce a turbid fluid. He believes that all milky fluids are due to an admixture of chyle and rejects the terms chyliform and pseudo-chylous as unwarranted.

M. A. Blankenhorn (1923) in a comprehensive paper supports Gandin. He showed experimentally that the turbidity is always due to fat and that not only the quantity but the fineness of the division is of the greatest importance. He maintains that neither protein nor protein complexes are ever the cause of turbidity of these effusions. Merely because by crude salting-out experiments previous observers obtained a final product of a lipoidprotein complex is no proof that in the suspension any such combination existed. When fats and protein are both in an alkaline medium; and hence freely suspended, there may be no relationship between them other than that of two separate dispersoids in the same continuous phase. The great difficulty found in separating them is due mainly to the similarity of their properties as colloids. Fat may be so finely divided as to assume the properties of colloids.

The following two cases of chylous effusion were under my observation at the same time :-

Case I

Male. W.B., age 48 .

C.O. Pain in right chest for one month.

F.H. Nil relevant.

P.I. Nil.

P.H. Occupation, clerk.

H.P.C. Patient had not been well for six months, having complained of malaise and generalized lassitude. Six months prior to admission, he had had an attack of vomiting with marked constipation for one week which had been diagnosed as gastritis. For two months he had had a very slight cough with a small amount of mucoid expectoration. There had been no haemoptysis. For the last few weeks he had complained of a severe lancinating pain of pleural type in his right lower chest.

\section{Examination}

General nutrition good. No . pallor or cyanosis of skin or mucous membranes. No enlargement of thyroid or lymphatic glands or clubbing of fingers. No oedema of ankles. Temperature $101.8^{\circ} \mathrm{F}$. Pulse rate 120 per minute. Respiration 26 per minute.

Respiratory System

There were signs of effusion at the right base, extending as high as the third dorsal 
spine. No crepitations were heard. Left lung appeared normal clinically.

Nervous, cardio-vascular and alimentary systems were normal. Urine was normal.

Paracentesis thoracis was performed and 50 cc. of milky fluid were removed for examination. X-ray of chest showed a large pleural effusion with bilateral miliary tuberculosis.

Sputum was mucoid and contained no T.B.

\section{Pathological report on fluid}

Yellowish-white creamy fluid which appeared to be a perfect emulsion. The degree of opalescence varied with successive tappings. S.G. was 1.03 ; reaction alkaline. Fluid was odourless and no putrefaction occurred after keeping for many months. It was sterile and no sediment or clot formed on standing or centrifuging and it passed through filter paper unchanged. Microscopically numerous highly refractile granules were seen. On shaking with ether and potassium hydroxide the emulsion became almost clear. Chemical analysis showed :-

Total protein, $2.5 \mathrm{~g}$. per cent.

Total cholesterol, $66.6 \mathrm{mg}$. per cent. (Myers and Wardell technique, 1918.)

Chlorides, $520 \mathrm{mg}$. per cent.

\section{Subsequent course of the disease}

The temperature remained high until death five weeks after admission. It was of the continued type (minimum $\mathrm{roI}^{\circ}$ and maximum $\left.104^{\circ}\right)$.

His sputum later became muco-purulent but T.B. was never found although it was very carefully examined every day for the 14 days prior to death.

In an attempt to determine whether the milky effusion was chylous, chyliform or pseudo-chylous, the following experiments were carried out.

(I) The patient was given a high fat diet for three days and $20 \mathrm{cc}$. of fluid was removed from the chest on each of the three following days-the high fat diet being meanwhile continued. The fluid became more creamy and more yellow. Its total cholesterol content increased from $66.6 \mathrm{mg}$. per cent. to a maximum of $85 \mathrm{mg}$. per cent. But the experiment was far from conclusive as subsequent keeping the patient on a low fat diet for five days did not materially diminish the fat content of the fluid. The increase was probably due to a progress of the underlying tuberculous condition or may have been merely a manifestation of the spontaneous variability of composition at successive tappings said to be characteristic of pseudo-chylous effusions (Powell and Hartley, 1921).

(2) The patient was fed in addition to ordinary diet on pats of butter in which Sudan III powder was impregnated. The idea was that if the effusion came from the thoracic duct the Sudan III would stain the fat of the effusion in situ. Paracentesis was performed six, nine and 12 hours after the administration of the Sudan III. The fluid was unaltered. It was mixed with ether and the fat extracted but no Sudan III was present. Two weeks later the experiment was repeated using larger quantities of Sudan III. The result remained negative.

The patient's condition gradually deteriorated but he never became cyanosed. This is interesting in view of the stress laid by many clinicians upon cyanosis as an important diagnostic sign in miliary tuberculosis. Three days before death he became delirious and developed retention of urine.

\section{Posi mortem}

The right pleural cavity contained chylous fluid. There were a few miliary tubercles in the pleura covering both lungs which were studded with miliary tubercles. There was no caseation. Old scarring was present at the apex of the right lung.

The spleen and liver were not grossly enlarged but contained miliary tubercles. There was a large mass of hard glands in the posterior mediastinum. The thoracic duct appeared normal and the enlarged glands were not compressing it. There were no macroscopic changes noticed in the lacteals.

The miliary tubercules of the lungs, liver and spleen were confirmed microscopically and section of the glands showed caseous tuberculosis in spite of their apparent firmness.

\section{Case II}

Male. F.Y., age, 42.

C.O. Swelling of legs and abdomen for three months. 
F.H. Nil relevant.

P.I. Two years previously he had been admitted to another hospital with right sided pleurisy. X-ray showed tuberculosis of the right upper zone, but his sputum was negative. Six months later his sputum was reported positive for the first time. An A.P.T. was carried out seven months after this and patient left hospital against advice five months after A.P.T. therapy had been started. The details of the A.P.T.s are not obtainable. He was readmitted seven months later with a haemoptysis. His sputum was then negative. After a further two months stay in hospital he again left against advice. During this two months his temperature was normal.

\section{Examination}

General nutrition fair. Pallor but no cyanosis of skin or mucous membranes. Orthopnoea. Clubbing of fingers. There was very extensive oedema of lower limbs, penis and scrotum.

\section{Respiratory System}

Trachea markedly displaced to the right. There were signs of large right pleural effusion at right base, and cavitation at right apex (? due to tracheal displacement).

\section{Alimentary System}

Superficial depapillating glossitis. Marked ascites. Liver and spleen were not palpable.

Cardio-vascular and nervous systems appeared normal. Urine contained albumin but no casts. Fractional Test Meal showed a complete achlorhydria. Blood Count was as follows :-

$$
\begin{aligned}
& \text { R.B.C.s, 3,100,000 Hb., } 58 \text { per cent. } \\
& \text { Colour Index, } 0.48 \\
& \text { W.B.C.s, 20,000 Polymorphs, } 84 \text { per cent. } \\
& \text { Small lymphocytes, } 13 \text { per }
\end{aligned}
$$

No sputum was ever obtained for examination in spite of administration of large doses of potassium iodide and later an ammonium carbonate mixture. This may have been due to the condition of his lung found postmortem, but a contributory factor was probably the patient's often expressed fear of being diagnosed as tuberculosis and so sent to a sanatorium. He himself denied any previous illnesses, the details of his past medical history having been given to me by his wife.

There were $60 \mathrm{cc}$. of creamy fluid removed from his right chest for examination. The characteristics of the fluid were as follows :-

It was more yellow but less opalescent than the fluid of Case I ; alkaline; a slight clot formed on standing for 48 hours but the fluid was sterile and did not putrefy after keeping for several months. It did not alter much with successive tappings. Passing through filter paper produced no change in the emulsion, but the turbidity was completely removed by addition of ether and potash. Microscopically numerous highly refractile granules were seen.

Chemical investigation showed :-

Total protein ..... $0.4 \mathrm{~g}$. per cent.

Total cholesterol .. 73.I mg. per cent. Chlorides ........ 940 mg. per cent.

Six pints of similar fluid were removed from: his abdomen.

Similar Sudan III experiments as described in Case I were carried out in this patient with similar negative results.

X'-ray of chest showed a dense opacity of almost the whole of the right chest with marked deviation of the trachea and slight displacement of the heart to the right. In the upper part of the opacity there were several rounded areas much more translucent than the opacity. The left lung was clear and there was no gross cardiac enlargement. Unfortunately a lateral view was not taken. The film was suggestive of collapse of the whole of the right lung with cavitation of the upper lobe.

He died 25 days after admission. During this period his temperature remained normal and respiratory rate varied from 18 to 26 , and pulse rate from 90 to 120 .

\section{Post-mortem findings}

The left lung showed oedema at its base but was otherwise normal. The left pleura was also normal.

The right lung was less than half the size of the left. The pleura covering it was one-third 
of an inch thick and the lung itself ' was carnified into an almost airless fibrous tissue mass. The upper lobe contained several thick-walled cavities and there were a few small tubercles scattered throughout the upper lobe. Smears from these cavities showed T.B. and streptococci. The right pleural cavity contained chylous fluid. The thoracic duct appeared normal.

The peritoneal cavity contained a large chylous effusion but the peritoneum itself was normal. There was no evidence of venous or lacteal obstruction or glandular enlargement. The liver apart from fatty change appeared normal, and the spleen showed no macroscopic change. The lung on section showed typica! fibrocaseous tuberculosis.

\section{Comments}

To which of the three types of 'chylous' fluid did these effusions belong? Powell and Hartley (I92I) give I8 differences between 'true chylous' and 'pseudo-chylous' effusions. Judged by these criteria Case I has nine points in favour of its being chylous and six for pseudo-chylous (three differences enumerated by Powell and Hartley were not tested). Case 2 has ten points for true chylous and five points for pseudo-chylous. The necessity for describing so many points of differentiation throws some doubt on the validity of the classification. All but two are mere differences of degree-the 'chylous' being more concentrated than the 'pseudochylous.' As Blankenhorn says, 'The classification must fail when there are so variable factors which cannot be evaluated such as the presence of infection, transudation of body fluids or alteration in fluid intake.' It appears to me impossible to place with certainty either of the above two cases into any of the three groups.

Case $I$ is of additional interest because there has been, as far as I am aware, no case previously recorded of a chylous effusion occurring with miliary tuberculosis.

The appearance of the right lung in Case 2 is worthy of comment. I presume it to have been caused mainly by inadequately supervised or controlled A.P.T. therapy. The A.P.T., rather than resting the lung, by squeezing it into a firm mass of functionless tissue, was a virtual lobectomy.

\section{Summary}

(I) Two cases of chylous effusion are reported-the first apparently the only case recorded occurring in a pati entwith miliare tuberculosis.

(2) Certain experiments with Sudan III and changes in diet are described.

(3) The value of the usual subdivision of chylous effusions is questioned and the work of Gandin and Blankenhorn urging its discontinuance is cited.

\section{BIBLIOGRAPHY}

BLANKENHORN, M. A. (1923), Arch. Intern. Med., Vol. xxxii. GANDIN (1913), Ergebmisse d. innern. Med. u. Kinderheilkunder, Berlin, xxii, 227.

MYERS and WARDELL (1918), fourn. Biol. Chem., xxxvi, 147. OSLER'S 'Principles and Practice of Medicine' (1935), ed. McCrae, p. 660, Appleton.

'Oxford Medicine' (1927), ii, 187.

POWELL and HARTLEY (I921), 'Diseases of the Lungs,' p. I67, H. K. Lewis.

PRICE, 'Text Book of Medicine' (1936), p. 1233, Oxford Press. 